\title{
Risk-targeted hazard maps for Spain
}

\author{
A. Kharazian' ${ }^{1}$ S. Molina ${ }^{1,3} \cdot$ J. J. Galiana-Merino ${ }^{2,4} \cdot$ N. Agea-Medina ${ }^{1}$
}

Received: 9 February 2021 / Accepted: 21 July 2021 / Published online: 29 July 2021

(c) The Author(s) 2021

\begin{abstract}
Many studies have demonstrated that the design of structures in a region through the uniform hazard principle does not guarantee a uniform collapse risk. Even in regions with similar Peak Ground Accelerations (PGAs) corresponding to the same mean return period, the seismic risk in terms of collapse probability will be significantly different mainly due to the shape of the hazard curves as well as uncertainties in structural capacities. In this paper, risk-targeted hazard mapping is being explored in peninsular Spain using a recently updated seismic hazard map. Since risk targeting involves multiple input parameters such as the model parameters of fragility curves, their variability was considered through their probability distribution as observed in reinforced concrete (RC) moment frame buildings, representing the most common building typology in Spain. The influence of the variation of these parameters on the risk results were investigated, and different assumptions for estimating the model parameters of fragility curves are illustrated. These assumptions were included in a fixed (generic) fragility curve or building-site-specific fragility curves. Different acceptable damage states (i.e., collapse and yielding) were considered concerning Spain's seismicity level. Finally, the maps for risk-targeted design ground motions and risk coefficients are presented. It is outlined that the employment of risk-targeted analysis leads to the modifications for existing design ground motions due to the different shape of the hazard curves across Spain and considering the uncertainty of structural capacity. Moreover, it is found that using the building- and site-specific fragility curves could result in a more uniform seismic risk across the country.
\end{abstract}

Keywords Seismic hazard $\cdot$ Earthquake engineering $\cdot$ Collapse probability $\cdot$ Risk targeting $\cdot$ Fragility models

\section{Introduction}

Seismic hazard assessment and structural design are continually evolving, as evidenced by the rapid development of new procedures illustrated by the Pacific Earthquake Engineering Research Center (PEER). Numerous studies have aimed to integrate the principle of probability into seismic performance evaluation, taking into account the uncertainties related to seismic input and structural properties, capacity, and models (Dolšek 2009; Liel et al.

A. Kharazian

alireza.kharazian@ua.es

Extended author information available on the last page of the article 
2009). To estimate the seismic demand at a specific location, most of the seismic design codes rely on a defined return period (for example, $10 \%$ in 50 years) of a certain ground motion intensity measure. The decision to design a structure following a uniform hazard level is based on the idea that a process like this leads to the same annual collapse risk regardless of the structure's geographical location. Multiple studies have recently demonstrated that a design-based earthquake determined on a uniform hazard theory does not necessarily lead to the design of structures with a consistent risk of collapse in different areas. These inconsistencies are due to the different shapes of the hazard curve for different regions and uncertainties in the yielding or collapse capacity of structures (Luco et al. 2007) arising from a set of factors, such as differences in material properties and, design, amongst others. This uncertainty can also be raised from the record-to-record variability corresponding to the demand (e.g., uncertainty in ground motion). Hence, a structure can collapse due to a different ground motion than what it was designed for. Moreover, as the shape of the hazard curve depends on the site's location, even buildings designed for the same ground motion will have different collapse probability distributions.

Based on the work done by Luco et al. (2007), the estimation of a design ground motion to provide a constant level of risk would be more consistent by using a uniform risk assumption. This algorithm was used to present the risk-targeted maximum considered earthquake (MCE) ground motion (ASCE 2016). Accordingly, using the proposed method, Douglas et al. (2013) presented a risk-targeted seismic design map for France. In the study performed by Silva et al. (2016), various parameters involved in the development of risktargeted design maps were analysed, and maps for Europe were created using the SHARE seismic hazard results (www.share-eu.org). A risk-targeted map of Romania was developed by Vacareanu et al. (2018) using the hazard models developed by Pavel et al. (2016). Spillatura (2018) applied both site- and structure-specific fragility curves to estimate the risk-targeted design ground motion. Iervolino et al. (2018) investigated the risk of collapse in residential and industrial constructions in compliance with the Italian code. They illustrated that seismic safety tends to decrease with increasing seismic hazard at the building site, despite the homogeneous return period of excess seismic design ground motion. Douglas and Gkimprixis (2018) presented a review of this state-of-the-art technique, highlighting efforts to better constrain some of the input parameters. Besides, the authors discussed the problems in the practical implementation of this approach and the alternative paths forward. Zaman and Ghayamghamian (2019) conducted a probabilistic seismic hazard analysis, and a risk-targeted map for Tehran was provided based on the derived hazard curves. Taherian and Kalantari (2019) presented a risk-targeted seismic design map for Iran, considering the seismic hazard models from different seismic hazard maps. In recent work, Taherian and Kalantari (2021) performed a risk-targeting analysis for a case study of Iran for two hazard levels, i.e., design ground motions with mean return periods of 475 and 2475 years, respectively. To evaluate alternative approaches, Gkimprixis et al. (2019) performed a review and comparison of the existing procedures concerning the implementation of uniform-risk concepts in the performance-based design of structures. Among these, one based on the use of risk-targeted behaviour factors (RTBFs) has been recently considered to develop future versions of Eurocode 8 (EN-1998 2005). Douglas et al. (2019) demonstrated the effects of the RTBF approach when applied to the concept of risk-targeted maps for Italy.

While some research has been carried out on the importance and influence of input parameters in risk analysis, only a few studies, e.g., Martins et al. (2018) and Ulrich et al. (2014), have attempted to consider the distribution of these parameters considering their variability through this probability framework in risk targeting analysis. In this study, we 
develop new risk-targeted seismic design maps for Spain contemplating two different damage states, i.e., collapse and yielding. This research aims to determine whether there would be a significant variation in the current design's PGA values while considering the uniform risk assumption. Using an updated seismic hazard in peninsular Spain based on the recent study by IGN-UPM Working Group (2013) and the employment of variability in model parameters of fragility curves, the risk-targeted ground motion distribution was estimated for the region. It should be noted that these maps were obtained for the design of new structures using seismic design codes such as Eurocode 8. Moreover, we assumed that the most common buildings in Spain are reinforced concrete (RC) moment frame buildings.

\section{Seismic hazard model}

Spain is a country of low to moderate seismic hazard when compared to other European countries such as Italy or Greece. However, the country has suffered several damaging earthquakes in the past, the most important events being: the 1829 Torrevieja earthquake with a maximum intensity IX-X and Mw 6.6, and the 1884 Arenas del Rey earthquake with a maximum intensity IX-X and Mw 6.5 (Mezcua et al. 2004). Therefore, the first national seismic building design code using a probabilistic seismic hazard map was approved in 1994. Later, the code's seismic hazard map was updated after the damaging earthquakes that occurred in the south-east of Spain, namely the 1999 Mula earthquake, the 2002 Bullas earthquake, the $2005 \mathrm{La}$ Paca earthquake, and the 2011 Lorca earthquake, respectively, with moment magnitudes between 4.7 and 5.2.

The new seismic hazard map (IGN-UPM Working Group 2013) was the result of a project carried out collaboratively by the National Geographic Institute (IGN) and the Earthquake Engineering Research Group of the Technical University of Madrid (UPM). The results were computed as PGA for four annual probabilities of exceedance (i.e., return periods of 95, 475, 975, and 2475 years, respectively). However, as more annual probabilities of exceedances are needed to better define the slope of the hazard curve, we have computed an updated seismic hazard map obtaining 20 values of annual probabilities of exceedance for corresponding PGAs. Here, we used the seismic zoning provided by ZESIS (Garcia-Mayordomo 2015; IGME 2015) and the activity rate, b-parameters, maximum magnitude, and ground-motion prediction equations suggested by the IGN-UPM Working Group (2013) to compute the seismic hazard map for peninsular Spain in a grid of $0.1 \times 0.1$ degrees using the software R-CRISIS (Ordaz et al. 2013). The whole grid has 5249 sites, for which the probabilistic seismic hazard assessment (PSHA) was obtained in terms of PGA for rock site conditions (Fig. 1). A comparison of our results with the previous ones obtained by the IGN-UPM Working Group (2013) was conducted to assure that the differences were not significant (i.e., lower than $30 \mathrm{~cm} / \mathrm{s}^{2}$ in most of the cases and with a similar shape).

Figure 2 represents the seismic hazard curves of PGA in terms of annual probability of exceedance for some of the cities with the highest seismic hazard, i.e., Valencia, Alicante, Murcia, Almeria, Granada, and Malaga (Fig. 1).

Since the shape of the hazard curve is one of the important parameters in risk-targeted analysis, we estimated the distribution of local hazard curve slopes for seismic actions between 2475 and 475 years (Jalayer and Cornell 2003) for each site in peninsular Spain (Fig. 3). At first glance, this may be perceived that at the national level, not much variation can be expected in risk-targeted design ground motions due to the almost similar slope of 


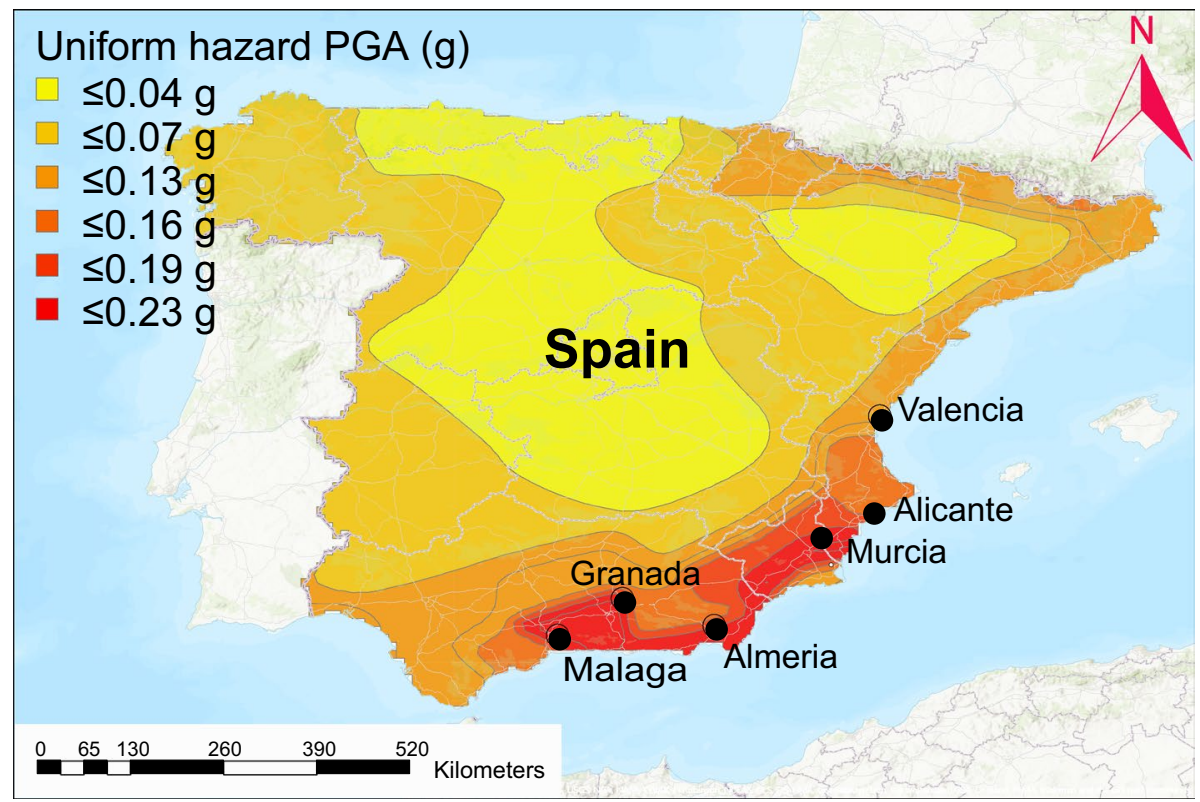

Fig. 1 Uniform hazard design ground motion map (UHGM) of peninsular Spain (PGA(g) at rock) for 0.1 exceedance probability in 50 years (corresponding to a return period $=475$ years)

the hazard curves. A few important points should be made here. A simple look at Fig. 2 reveals that no curves can be approximated by a line; hence computing the slope of the hazard curve is a biased process. Moreover, a small variation in the slope can cause a large difference in the risk of collapse. Nevertheless, the risk-targeted design ground motions depend not only on the shape of the hazard curve but also on the input parameters of the related fragility curve and the acceptable structural performance.

\section{Computing risk-targeted ground motions}

To perform a risk-targeted analysis, the fragility curve corresponding to the investigated structural building typology must be developed. In this approach, a fragility curve should cover the vulnerability of a certain building typology covering a broad variation of individual structures. On the other hand, developing these curves for a large number of building typologies and locations is time and cost consuming. Hence, the generic collapse fragility curves will be used for all building classes. It should be noted that the provided curves must be sufficiently generic to capture all possible levels of vulnerability (Douglas et al. 2013). The fragility function is conditional upon the values of the design ground motion. It outlines the conditional probability of reaching or exceeding a certain limit state, which, in the present study, relates to the yield damage state and the collapse of a structure for a given design ground motion with a specific return period (RP). In this study, the 475and 95-year RP were implemented (i.e., 10\% probability of exceedance in 50 years and $10 \%$ probability of exceedance in 10 years, respectively). These RPs are reference seismic actions in Eurocode 8 (EN-1998 2005), contributing to the criteria for the no-collapse and 


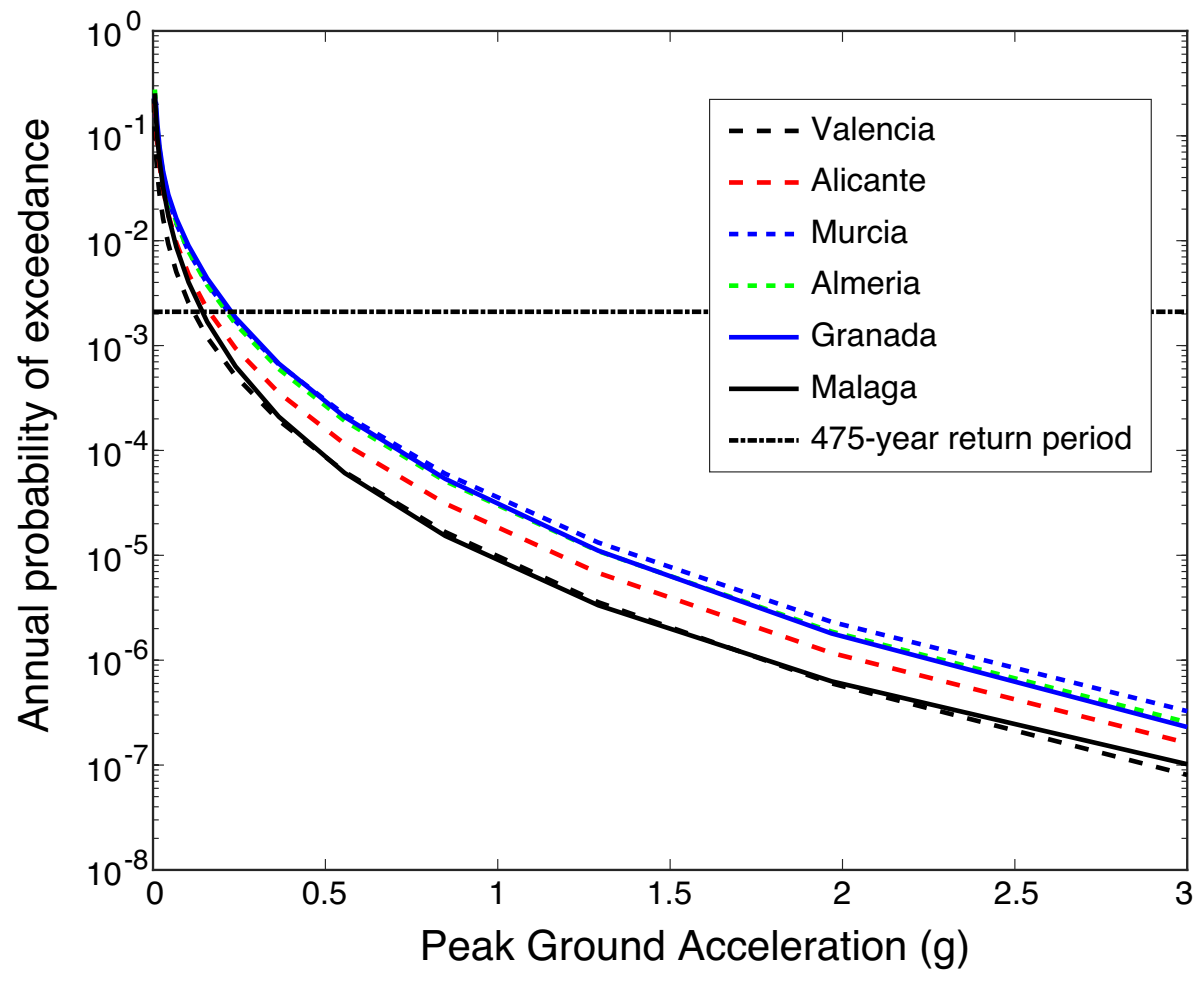

Fig. 2 Seismic hazard curves for six selected cities of Spain

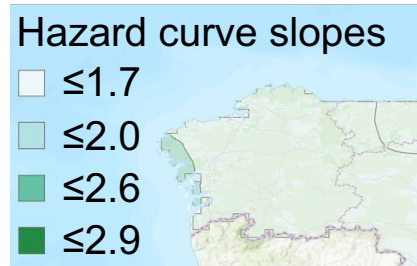

\section{Spain}
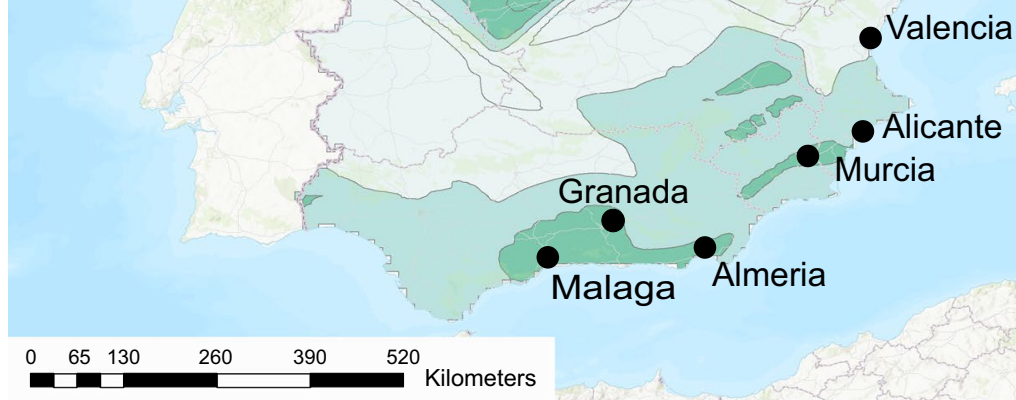

Fig. 3 Distribution of local hazard curve slopes 
damage limitation requirements. The fragility functions are presented as lognormal distributions with two parameters: the median value of a desired intensity measure, e.g., PGA with $50^{\text {th }}$-percentile of a probability distribution, and the logarithmic standard deviation of PGA $(\beta)$. However, the fragility curve can be characterised by any other percentile of the probability distribution (i.e., X-percentile where $\mathrm{X}$ refers to the $\mathrm{P}_{\mathrm{c}} \operatorname{lgm}$ or $\mathrm{P}_{\mathrm{y}} \operatorname{lgm}$ ) and $\beta$. Throughout this manuscript, the terms " $\mathrm{P}_{\mathrm{c}} \mid \mathrm{gm}$ " and " $\mathrm{P}_{\mathrm{y}} \mid \mathrm{gm}$ " will refer to the conditional probability of collapse and to the probability of exceeding yield damage state at the design ground motion, respectively. The former parameter $(\beta)$ considers several causes of capacity uncertainty, such as record-to-record variability, uncertainty in the definition of the damage state, and ideally other causes such as human errors, which cannot be supported by the most advanced numerical models (Silva et al. 2016; Sousa et al. 2016).

It should be outlined that Eurocode 8 provides no guidance regarding to the development of fragility curves of structures designed following EC8 provisions. So far, previous studies have suggested different values for the parameter $\beta$. As an example, Luco et al. (2007) used a $\beta$ value of 0.8 , while Douglas et al. (2013) suggested a value of 0.5. A $\beta$ value of 0.6 was considered in the study by Silva et al. (2016), while Vanzi et al. (2015) used a value of 0.2 . It is important to note that using a higher value of $\beta$ (e.g., more than 0.8 ) provides a low probability of collapse even in highly seismic regions, which seems to be an unrealistic scenario. On the other hand, assuming low values of $\beta$ (e.g., less than 0.2) leads to steeper collapse fragility curves that could provide a $100 \%$ probability of collapse even at low ground motion levels.

The estimation of $\mathrm{P}_{\mathrm{c}} \operatorname{lgm}$ or $\mathrm{P}_{\mathrm{y}} \operatorname{lgm}$, requires the design and evaluation of many structures and a wide range of hazard levels. Several studies have postulated different values of conditional probability either for the collapse or yielding damage state at the design ground motion. For instance, Douglas et al. (2013) suggested a $\mathrm{P}_{\mathrm{c}} \operatorname{lgm}$ value of $10^{-5}$, while Silva et al. (2016) used a value of $10^{-3}$. Ulrich et al. (2014) demonstrated that for a design ground motion between $0.07 \mathrm{~g}$ and $0.3 \mathrm{~g}$, the probability of yielding $\left(\mathrm{P}_{\mathrm{y}} \mid \mathrm{gm}\right)$ varies from 0.14 to 0.85 , respectively. Moreover, in their study, they proposed a value for $\mathrm{P}_{\mathrm{c}} \operatorname{lgm}$ with an order of $10^{-7}$ for low, frequent design ground motion levels and $10^{-5}$ for higher and rarer design ground motions. However, Silva et al. (2016) believed that this range of probability of collapse (i.e., $10^{-7}$ to $10^{-5}$ ) is too low for ordinary structures. Luco et al. (2007) selected a $10 \%$ probability of collapse under MCE, which corresponds to the probability of collapse at the 475-year ground motion ranging from $10^{-2}$ to $10^{-3}$. Fajfar and Dolšek (2012) computed the value of $P_{c} \operatorname{lgm}$ in the range of $10^{-4}$ to $10^{-5}$, and Vanzi et al. (2015) used the value of $1.3 \times 10^{-6}$ for the probability of collapse under gravity loads. Taherian and Kalantari (2019) defined $\mathrm{P}_{\mathrm{c}} \mathrm{gm}=0.01$ and $\beta=0.8$ for Iranian code-conforming buildings.

According to the method proposed by Luco et al. (2007), Kennedy (2011), and Douglas et al. (2013), as well as using the given seismic hazard curve (Mean Annual Frequency (MAF) of exceeding various values of PGA) and fragility function which is expressed as a probability density function (PDF), the mean annual rate of exceeding the damage state (MAF) is determined using the following classic convolution products given by Kennedy (2011):

$$
M A F=\int_{0}^{+\infty} G(s) \cdot \frac{d F(s)}{d s} d s
$$

where $F(\mathrm{~s})$ is the fragility function (conditional probability of collapse or yielding for a given ground motion), and $G(\mathrm{~s})$ is the annual rate of exceedance of a given intensity 
measure level. The integration in Eq. (1) does not have a closed-form solution (Eads et al. 2013); therefore, an iterative process is required to calculate risk-targeted design ground motions. As suggested by Eads et al. (2013) and Silva et al. (2016), the mean annual rate of exceeding the damage state (e.g., collapse or yielding) will be computed by dividing both the fragility and seismic hazard curves into a large number of segments and then by numerically integrating the distribution. The main objective is to estimate ground motions that are consistent with the target risk (i.e., the accepted annual rate of exceeding the damage state). Therefore, it is necessary to define an acceptable level of seismic performance, expressed as an annual collapse risk or an annual probability of exceeding the yielding depending on the desired structural performance. Regarding the acceptable annual collapse risk, different suggestions have been postulated in other studies and seismic codes. For example, the American Society of Civil Engineers (ASCE 2016) proposed a value of $2.0 \times 10^{-4}$ for the United States. This value was also considered by Luco et al. (2007) and Taherian and Kalantari (2019). Douglas et al. (2013) suggested using $1.0 \times 10^{-5}$ as a reasonable value. In the research carried out by Silva et al. (2016), the value of $5.0 \times 10^{-5}$ was established as an acceptable annual risk of collapse.

Nevertheless, this threshold (i.e., the acceptable annual risk of collapse) depends on the importance of the structures (Douglas et al. 2013). It should be estimated by policymakers, sociologists, and other related decision-makers, with the help of engineers. Also, regarding the design of new structures, Douglas et al. (2013), Silva et al. (2016), and Martins et al. (2018) suggested that potential losses due to more frequent earthquakes should be considered. For example, in Eurocode 8, the damage limitation has been introduced for ground motions with a $10 \%$ probability of exceedance in 10 years ( 95 -year return period). However, bearing in mind that this cannot lead to a uniform risk across the area or the structures. Hence it is recommended that risk-targeted hazard maps should be developed for different levels of risk, e.g., yielding or collapse limit states.

Therefore, in the iterative process, the value of the design ground motion changes in each step until reaching the expected value of the acceptable annual probability of exceeding the damage state. The obtained design ground motion at the final step will be the risktargeted ground motion. Based on the study by Luco et al. (2007), for each site, the risk coefficient $(\mathrm{CR})$ is calculated by dividing the former value obtained and the uniform hazard design ground motion with a specific mean return period.

\section{Estimation of input parameters $\left(P_{c} \mid g m, \beta\right.$, and acceptable collapse rate)}

The estimation of $\mathrm{P}_{\mathrm{c}} \mathrm{gm}$ has been the object of restricted studies since it involves assessing a wide variety of structures and analysing a diverse range of hazard thresholds. The determination of the $\mathrm{P}_{\mathrm{c}} \operatorname{lgm}$ content from a comprehensive review of the fragility models existing in the literature is impractical because the modelling process and related design ground motions are not commonly recorded. Moreover, in the documentation related to the Spanish seismic regulations, there is almost no guidance on what value to choose for the level of acceptable risk or conditional probability of collapse for a given design PGA and $\beta$.

In most recent studies, such as Gkimprixis et al. (2020) and Crowley et al. (2018), the building-specific fragility functions have been implemented in risk-targeted analyses to avoid overestimating the values of collapse risk specifically for low hazard regions. Considering the variability of $\mathrm{P}_{\mathrm{c}} \operatorname{lgm}$ and $\beta$ in risk-targeted analysis, we decided to 
develop random variable distribution functions. The normal distributions of $\mathrm{P}_{\mathrm{c}} \operatorname{lgm}$ and $\beta$ were prepared according to the results obtained by Martins et al. (2018). In their work, Martins et al. (2018) developed a set of regular RC moment frame structures designed with the most up-to-date European codes for different ground-motion levels. Each structure was represented using a tri-dimensional finite element model and tested against a set of ground-motion records using nonlinear dynamic analyses. They considered two damage states: yielding (onset of structural damage) and structural collapse. Variability in the structural design was introduced to propagate the building-to-building variability to the risk estimates. Hence, in this study, we consider RC moment frame buildings as a common typology in Spain.

Consequently, based on the previous assumptions and the results obtained by Martins et al. (2018), and considering the simultaneous effects of two parameters on the fragility curve, a multivariant probability distribution was developed, as displayed in Fig. 4a. This distribution can capture the uncertainty in the parameters mentioned above in risk-targeted analysis. It should be outlined that Martins et al. (2018) and Silva et al. (2016) recommended considering the correlation between $P_{c} \operatorname{lgm}$ and $\beta$ to avoid developing unrealistic fragility curves. For instance, the higher values of $\beta$ in high seismic hazard zones lead to flatter fragility curves and, consequently, a low probability of collapse even for higher ground motion levels. Therefore, the correlation between $\mathrm{P}_{\mathrm{c}} \operatorname{lgm}$ and $\beta$ was considered to develop the multivariant probability distribution shown in Fig. 4a.

This multivariant probability distribution was employed to generate 100 random fragility curves corresponding to different random values of $\mathrm{P}_{\mathrm{c}} \operatorname{lgm}$ and $\beta$. It should be mentioned that the decision for sampling 100 fragility curves was made after getting a statistical convergence. Moreover, when sampling the parameters, the correlation between $P_{c} \operatorname{lgm}$ and $\beta$ was also considered. After considering the mean fragility curve (Fig. 4b), we recalculated the annual risk of collapse across Spain once for all 100 developed $\mathrm{P}_{\mathrm{c}} \operatorname{lgm}$ and $\beta$; the same process was then repeated but using the fragility function developed by Crowley et al. (2018), according to the methodology described in the previous section. Crowley et al. (2018) utilised the parameters given by Martins et al. (2018), but also included the level of seismic hazards to account for the variation in these parameters based on the local seismic hazard. The obtained results were used to estimate the acceptable annual risk of collapse.

(a)

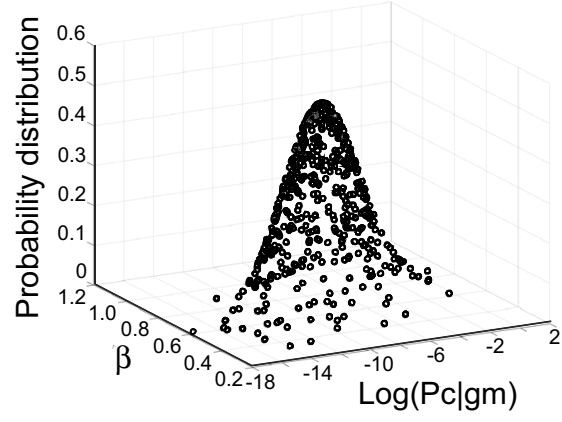

(b)

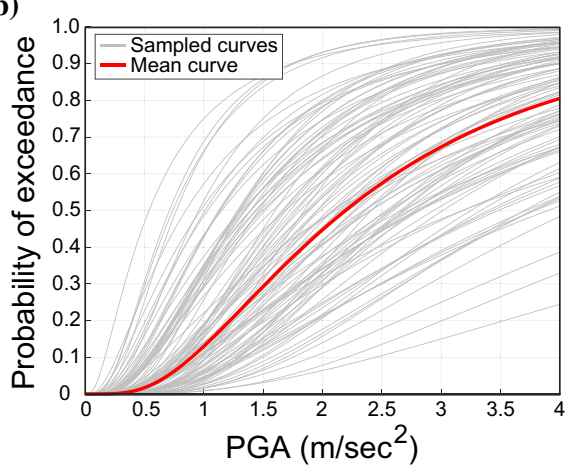

Fig. 4 a Multivariant normal distribution for random variables of $\beta$ and natural logarithmic $P_{c} \operatorname{lgm}$ (correlation coefficient $=0.582$ ), $\mathbf{b}$ Example of sampled and mean fragility curves using random values estimated through the multivariant PDF at design $\mathrm{PGA}=0.2 \mathrm{~g}$ 
Table 1 Statistical results obtained from the risk analysis for Spain $\mathrm{P}_{\mathrm{c}} \operatorname{lgm}=3 \times 10^{-4}$ and $\beta=0.7$ (mean fragility curve)

\begin{tabular}{llllll}
\hline & Max & Min & Median & Mean & CoV* $^{*}$ \\
\hline Annual collapse risk & $1.7 \times 10^{-5}$ & $2.1 \times 10^{-7}$ & $8.0 \times 10^{-6}$ & $7.8 \times 10^{-6}$ & 0.51 \\
$\begin{array}{l}\text { Probability of collapse in } \\
\text { 50 years }\end{array}$ & $8.4 \times 10^{-4}$ & $1.1 \times 10^{-5}$ & $3.9 \times 10^{-4}$ & $3.8 \times 10^{-4}$ & 0.52 \\
\hline
\end{tabular}

*CoV: Coefficient of Variation

Table 2 Statistical results obtained from the risk analysis for Spain (considering 100 random values of $\beta$ and $\mathrm{P}_{\mathrm{c}} \operatorname{lgm}$ using the normal joint distribution for each site)

\begin{tabular}{llllll}
\hline & Max & Min & Median & Mean & CoV $^{*}$ \\
\hline Annual collapse risk & $2.7 \times 10^{-5}$ & $6.2 \times 10^{-7}$ & $1.16 \times 10^{-5}$ & $1.2 \times 10^{-5}$ & 0.50 \\
$\begin{array}{l}\text { Probability of collapse in } \\
\text { 50 years }\end{array}$ & $1.4 \times 10^{-3}$ & $3.1 \times 10^{-5}$ & $5.8 \times 10^{-4}$ & $6.0 \times 10^{-4}$ & 0.53 \\
\hline
\end{tabular}

*CoV: Coefficient of Variation

Regarding the acceptable annual risk of collapse, other studies and seismic codes have presented different suggestions as discussed in Sect. 3. Herein, we performed a similar analysis to the one undertaken by Luco et al. (2007) to estimate the acceptable annual collapse risk. To begin this process, the target probability of collapse was estimated through three different assumptions. In the first method, the fixed values of 0.7 and $3 \times 10^{-4}$ were assumed for $\beta$ and $\mathrm{P}_{\mathrm{c}} \operatorname{lgm}$, respectively. These values were calculated by obtaining an average over all the sampled $\beta$ and $P_{c} \operatorname{lgm}$. The annual risk of collapse for all 5249 sites was then calculated. Table 1 presents the statistical results of collapse probability across the country, considering the assumptions mentioned earlier.

Table 1 shows that the average annual risk of collapse is $7.8 \times 10^{-6}$, and the maximum and minimum values are $1.7 \times 10^{-5}$ and $2.1 \times 10^{-7}$, respectively. Therefore, it can be observed that in many areas, the values of the annual risk of collapse are different with respect to the average value of the risk rate $\left(7.8 \times 10^{-6}\right)$. Hence, the need for developing risk-targeted seismic design maps for the country becomes obvious.

As mentioned before, in the regions with similar design ground motion corresponding to a similar hazard level, the seismic risk in terms of collapse probability will be significantly different due to structural capacity uncertainties and mainly the shape of hazard curves. To illustrate this fact, we provide an example using the above assumptions made to generate fragility curves (i.e., $\beta=0.7$ and $\mathrm{P}_{\mathrm{c}} \operatorname{lgm}=3 \times 10^{-4}$ ). Figure 2 shows that the cities of Alicante and Malaga have almost the same design ground motion corresponding to the mean return period (RP) of 475 years (i.e., $\mathrm{PGA}=0.16 \mathrm{~g}$ and $0.14 \mathrm{~g}$, respectively). However, as noted, the disparity in the form of the hazard curve (Fig. 2) contributes to unequal values of the collapse probability $\left(\mathrm{P}_{c}\right)$ in 50 years, i.e., $\mathrm{P}_{c}=6.6 \times 10^{-4}$ and $\mathrm{P}_{\mathrm{c}}=4.7 \times 10^{-4}$ for Alicante and Malaga, respectively. This confirms that buildings designed for the same ground motion could have different values of collapse probability.

Once again, to consider all uncertainties due to the building-to-building variability, all the possible values of $\beta$ and $P_{c} \operatorname{lgm}\left(100\right.$ random values of $\beta$ and $P_{c} \operatorname{lgm}$ ) were extracted from the multivariant normal distribution. The annual risk of collapse across Spain was calculated. The obtained results are summarised in Table 2. 
Table 2 shows that the average annual risk of collapse is $1.2 \times 10^{-5}$, and the maximum and minimum values are $2.7 \times 10^{-5}$ and $6.2 \times 10^{-7}$, respectively. The mean value in Table 2 has the same order of magnitude as the value proposed by Douglas et al. (2013) (order of $10^{-5}$ ). Table 2 also shows the effect of the variability of $\beta$ and $\mathrm{P}_{\mathrm{c}} \operatorname{lgm}$ on the annual risk of collapse and the importance of considering this variability in the probabilistic framework.

In the third option, for every 5249 sites, the corresponding values of $\beta$ and $\mathrm{P}_{\mathrm{c}} \operatorname{lgm}$ were estimated according to the fragility curve matching the design ground motion at the site. These values were calculated through the results obtained by Martins et al. (2018) and Crowley et al. (2018). They established a relationship between the design ground motion and the median and logarithmic standard deviation of the collapse fragility functions. Then again, through the same procedure as the previous two methods, the minimum, maximum, median, mean value, and coefficient of variation of the annual collapse risk were determined. Table 3 shows the statistical results.

In the current study, the comparison of Table 1 with Tables 2 and 3 indicates that the value of $10^{-5}$ for the annual target risk of collapse is a logical estimate.

The collapse risk distribution was prepared across the peninsular territory to compare the methods used to introduce the building-specific fragility curve. Figure 5 shows the relation between the probability of collapse in 50 years and the design ground motion obtained from the uniform hazard ground motion map (UHGM) (Fig. 1). Figures 5a, c display the collapse probability achieved using the mean fragility curve (mean of 100 values of $\beta$ and $\mathrm{P}_{\mathrm{c}}$ lgm considering the multivariant normal distribution) and considering all 100 values of $\beta$ and $P_{c}$ ggm for each site, respectively. In the latter case, all 100 values of $\beta$ and $\mathrm{P}_{\mathrm{c}} \operatorname{lgm}$ were assumed to be similar for all 5249 sites. Figure 5b presents the relation between the probability of collapse in 50 years and the design PGA related to the fragility curves developed by means of the Crowley et al. (2018) functions for every 5249 sites namely building- and site-specific fragility curves.

The comparison of Fig. 5a, b, and c shows that building- and site-specific fragility curves provide a more coherent risk distribution (Fig. 5b) with the uniform hazard map, either for regions with low seismicity or moderate to high seismic areas. Figure 5a illustrates that considering one fragility curve (a fixed values of $\beta$ and $\mathrm{P}_{\mathrm{c}} \operatorname{lgm}$ ) overestimates the collapse risk values for low hazard areas and underestimates values for moderatehazard regions. This outline is consistent with the findings of Taherian and Kalantari (2021). Indeed, they also mentioned that considering the fixed values for $\mathrm{P}_{\mathrm{c}} \operatorname{lgm}$ would overestimate collapse risk for regions with low seismicity. Figure $5 \mathrm{c}$ shows that, while the problem of generating underestimated collapse probabilities in areas with high seismicity has been overcome, overestimated collapse probabilities are still observed in some areas with low seismicity. This observation could be due to the 100 fixed values of $\beta$ and $\mathrm{P}_{\mathrm{c}} \operatorname{lgm}$ for all 5249 sites.

Table 3 Statistical results obtained from the risk analysis for Spain (considering building-specific fragility curves for each site according to the design ground motion)

\begin{tabular}{llllll}
\hline & Max & Min & Median & Mean & CoV $^{*}$ \\
\hline Annual collapse risk & $2.0 \times 10^{-5}$ & $2.3 \times 10^{-9}$ & $5.0 \times 10^{-6}$ & $6.0 \times 10^{-6}$ & 0.83 \\
$\begin{array}{l}\text { Probability of collapse in } \\
\text { 50 years }\end{array}$ & $9.9 \times 10^{-4}$ & $1.1 \times 10^{-7}$ & $2.7 \times 10^{-4}$ & $3.2 \times 10^{-4}$ & 0.73 \\
\hline
\end{tabular}

*CoV: Coefficient of Variation 
(a)

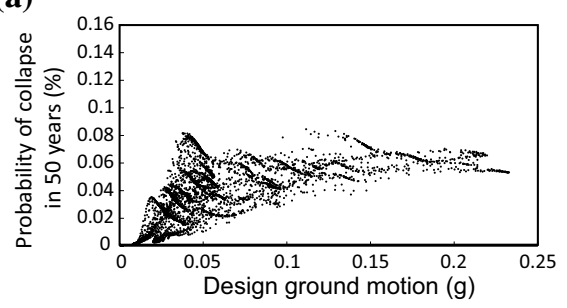

(b)

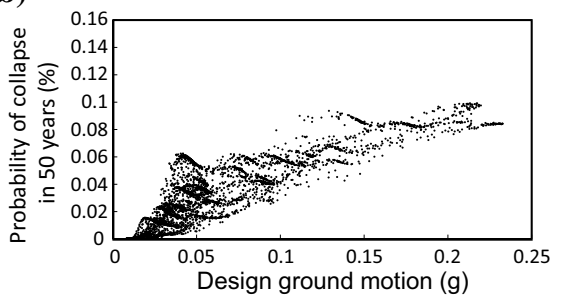

(c)

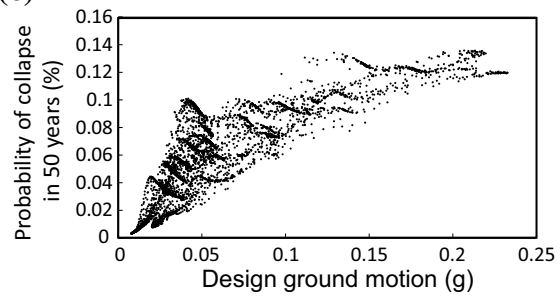

Fig. 5 Relation between design ground motion and probability of collapse in 50 years $(\%)$ a Fixed value for $\beta$ and $P_{c} \operatorname{lgm}\left(\beta=0.7\right.$ and $P_{c} \operatorname{lgm}=3 \times 10^{-4}$, b Crowley et al. (2018) fragility curves (building- and site-specific fragility curve), $\mathbf{c} 100$ fixed values of $\beta$ and $\mathrm{P}_{\mathrm{c}} \mathrm{gm}$ for each site obtained from the multivariant normal distribution

It should be considered that the calculation of risk-targeted ground motions using different fragility curves according to design ground motion for each site is computationally very time-consuming. Hence, it is preferred to use the relationship between the design ground motion and $\beta$ and the median value of building capacity to develop a building- and site-specific fragility curve for every desired site. According to this, it is recommended to introduce relationships between the design acceleration and the median and logarithmic standard deviation of the collapse fragility functions similar to those raised by Crowley et al. (2018) for other typologies and different areas. As shown in Fig. 5b, c, the results obtained are remarkably similar, confirming the accuracy of the multivariant normal distribution used in this paper.

Plots from Fig. 5 show the increase of the risk of collapse with the increase of ground motion. This outline is coherent with the findings of Iervolino et al. (2018). In their work, they showed that the seismic risk of buildings is directly related to the seismic hazard of the site. Moreover, as can be seen in Fig. 5, the results show some locations with identical design PGA but a very different probability of collapse. This discrepancy is due to the slope of the hazard curves.

\section{Results and discussion}

In this section, the risk analysis is performed assuming different fixed values of $\beta$ and $\mathrm{P}_{\mathrm{c}} \operatorname{lgm}$ to assess the effect of these parameters on the risk analysis. Then, the risk-targeted maps across peninsular Spain will be presented. For this purpose, once the average values of 0.7 and $3 \times 10^{-4}$ for $\beta$ and $P_{c} \operatorname{lgm}$ (related to the obtained random sampling using the multivariant normal distribution) are considered, then the building- and site-specific fragility curves are implemented. It should be noted that the considered value of $3 \times 10^{-4}$ for 
$\mathrm{P}_{\mathrm{c}} \operatorname{lgm}$ is consistent with the probability of collapse at the design ground motion for ordinary structures. This remark was also discussed by Martins et al. (2018) who mentioned that a low value of $\mathrm{P}_{\mathrm{c}} \operatorname{lgm}$ for ordinary structures could be a conservative value. Finally, $\mathrm{a}$ risk-targeted map corresponding to different structural performances is presented.

In the first step, a series of maps for peninsular Spain were generated to evaluate the effect of the two main input parameters, namely the standard deviation $\beta$ and the probability of collapse for a given design ground motion with a 475-year mean return period (defining the fragility function) on the risk-targeted ground motion. For this purpose, four sets of values for $\beta$ and $P_{c} \operatorname{lgm}$ were selected, i.e., $\beta \pm \sigma_{\beta}$ and $P_{c} \operatorname{lgm} \pm \sigma_{\text {Pclgm }}$ where $\sigma$ denotes the standard deviations of the $\beta$ and $\mathrm{P}_{\mathrm{c}} \operatorname{lgm}$ with respect to their mean values corresponding to their random normal distribution. Table 4 shows the values assigned for the $\beta$ and $\mathrm{P}_{\mathrm{c}} \operatorname{lgm}$. As mentioned in Sect. 4 , we used the value of $1.0 \times 10^{-5}$ for the acceptable annual risk of collapse, $\lambda_{c}$, for all the cases. Moreover, the correlation between these parameters was disregarded since we were just looking at the effect of these parameters on the results of risk analysis.

The four maps shown in Fig. 6 represent the risk-targeted ground motions corresponding to the annual collapse risk of $1.0 \times 10^{-5}$. The PGAs were calculated for different combinations of $\beta$ and $\mathrm{P}_{\mathrm{c}} \mathrm{lgm}$, according to Table 4 .

The comparison between Fig. 6a, d highlights that the larger values of $\beta$ result in lower risk-targeted ground motions (almost $40 \%$ reduction). Moreover, Fig. 6b, c also show a reduction of $19 \%$ when increasing the value of $\beta$. A general comparison of the two reduction rates demonstrates that the amount of reduction is more remarkable when a lower probability of collapse for a given ground motion is considered. This could be due to the shape of the fragility curve. In the case of a considerable value of $\beta$ and a small value of the probability of collapse for a given ground motion, the curve will be flatter and will show low values of collapse probability even in large earthquake scenarios; this situation is unrealistic and in most of the cases leads to low values of risk of collapse with respect to the target value. We have already mentioned that these values were only selected to examine the effects of change on these parameters. In addition, this issue outlines the importance of considering the correlation between $\beta$ and $\mathrm{P}_{\mathrm{c}} \operatorname{lgm}$. The risk-targeted ground motions in Fig. 6a, $\mathrm{b}$ show that for a given value of standard deviation, the design ground motion level leads to larger values by increasing the value of $\mathrm{P}_{\mathrm{c}} \operatorname{lgm}$. A comparison between Fig. $6 \mathrm{c}, \mathrm{d}$ displays the same trend as mentioned before. This trend is expected since, for instance, to achieve a target risk in high seismicity areas despite a high probability of collapse, the design ground motion must be increased.

In the next stage of this work, a ratio, namely the risk coefficient (CR), was employed to investigate the effects of variation of $\beta$ and $\mathrm{P}_{\mathrm{c}}$ lgm parameters on the risk-targeted ground motions with respect to the uniform hazard ground motion map (UHGM). CR is the ratio between PGAs, leading to the target probability of collapse and peak ground accelerations with the RP of 475 years (uniform hazard values). Like in the previous

Table 4 Different cases considered for risk analysis in Spain $\left(\sigma_{\beta}=0.1 \& \sigma\right.$ Pclgm $=5.9 \times 10^{-3}$ )

\begin{tabular}{llll}
\hline Number of case & $\beta$ & $\mathrm{P}_{\mathrm{c}} \operatorname{lgm}$ & $\lambda_{\mathrm{c}}$ \\
\hline Case 1 $\left(\beta+\sigma_{\beta} \& \mathrm{P}_{\mathrm{c}} \operatorname{lgm}-\sigma_{\mathrm{Pclgm}}\right)$ & 0.8 & $1.5 \times 10^{-5}$ & $1.0 \times 10^{-5}$ \\
Case 2 $\left(\beta+\sigma_{\beta} \& \mathrm{P}_{\mathrm{c}} \operatorname{lgm}+\sigma_{\mathrm{Pclgm}}\right)$ & 0.8 & $6.2 \times 10^{-3}$ & $1.0 \times 10^{-5}$ \\
Case 3 $\left(\beta-\sigma_{\beta} \& \mathrm{P}_{\mathrm{c}} \operatorname{lgm}+\sigma_{\mathrm{Pclgm}}\right)$ & 0.6 & $6.2 \times 10^{-3}$ & $1.0 \times 10^{-5}$ \\
Case $4\left(\beta-\sigma_{\beta} \& \mathrm{P}_{\mathrm{c}} \operatorname{lgm}-\sigma_{\mathrm{Pclgm}}\right)$ & 0.6 & $1.5 \times 10^{-5}$ & $1.0 \times 10^{-5}$ \\
\hline
\end{tabular}


(a)

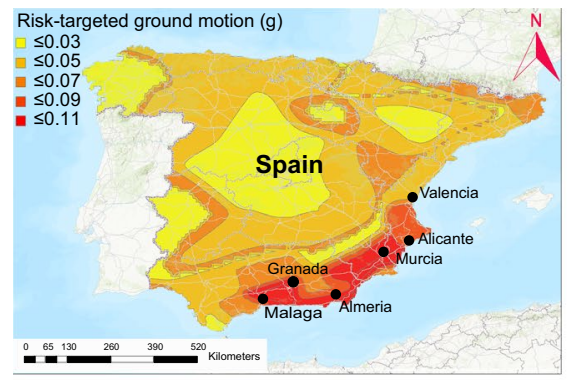

(c)

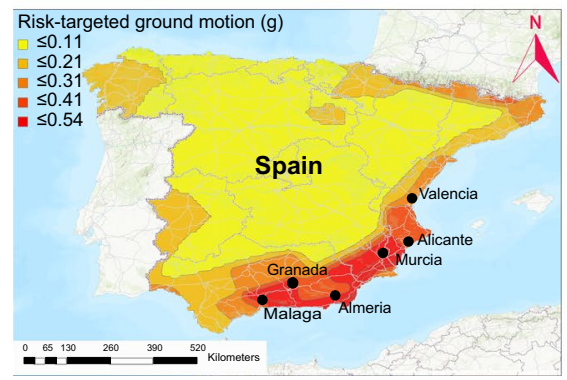

(b)

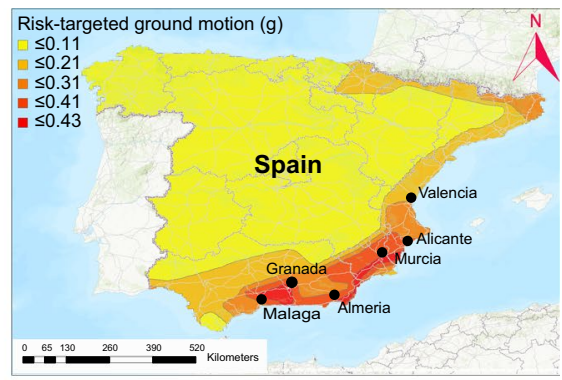

(d)

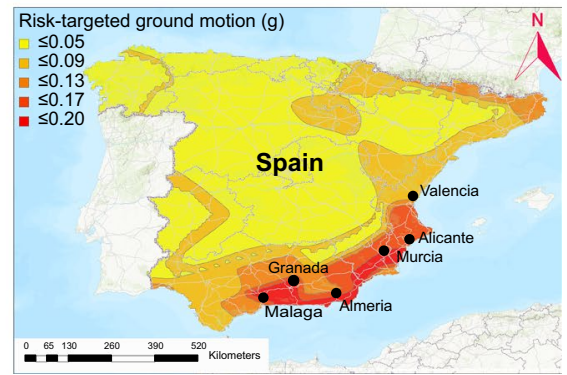

Fig. 6 Risk-targeted ground motion maps considering various values of $\beta$ and $\mathrm{P}_{\mathrm{c}} \operatorname{lgm}$ (case 1 to case 4 ) according to Table 4 for peninsular Spain a Case 1, b Case 2, c Case 3, d Case 4

evaluation, the risk-targeted analysis was performed considering the values of $\beta$ and $\mathrm{P}_{\mathrm{c}} \operatorname{lgm}$ mentioned in Table 4. Figure 7 shows the results of this assessment across peninsular Spain.

In Fig. 7, a value smaller than one indicates that the risk-targeted design ground motion is lower than the design ground motion corresponding to the uniform hazard. The distribution of risk coefficients across Spain (Fig. 7a,d) shows that the larger the $\beta$ value (i.e., $\beta+\sigma_{\beta}$ ), the lower the risk-targeted design ground motion relative to the uniform hazard map (Fig. 1). Figure 7b, c show the same trend. In addition, the evaluation of these four maps in Fig. 7 illustrates that the modification of design ground motions is more considerable in high seismic regions (e.g., in the south and southeast of peninsular Spain) than in areas of lower seismicity.

In the next step, as mentioned before, assuming $\beta=0.7$ and $P_{c} \operatorname{lgm}=3 \times 10^{-4}$ and then considering the building- and site-specific fragility curves for each of the 5249 sites, the risk-targeted ground motion maps are presented. A target annual collapse risk of $1.0 \times 10^{-5}$ was considered for all analyses. The results of these analyses are shown in Figs. 8 and 9. Figures $8 \mathrm{a}$ and $9 \mathrm{a}$ display the distribution of risk-targeted design ground motions, while Figs. $8 \mathrm{~b}$ and $9 \mathrm{~b}$ show the distribution of risk coefficients for peninsular Spain.

As it can be seen in Fig. 8a, the risk-targeted ground motion varies between $0.008 \mathrm{~g}$ and $0.25 \mathrm{~g}$, with an average value of $0.061 \mathrm{~g}$. According to Fig. 9a, the adjusted design ground motion varies between $0.008 \mathrm{~g}$ and $0.29 \mathrm{~g}$, with a mean value of $0.062 \mathrm{~g}$. According to Figs. $8 \mathrm{~b}$ and $9 \mathrm{~b}$, we can see that in most of the central, western and northwestern 
(a)

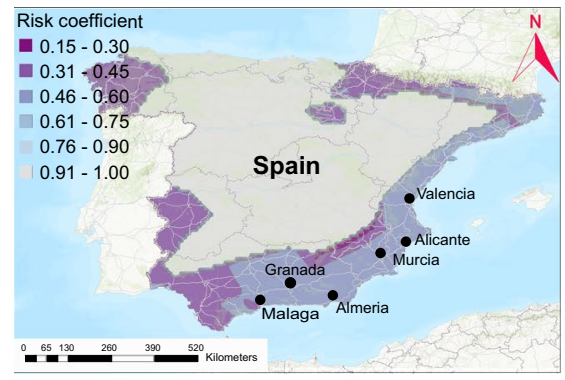

(c)

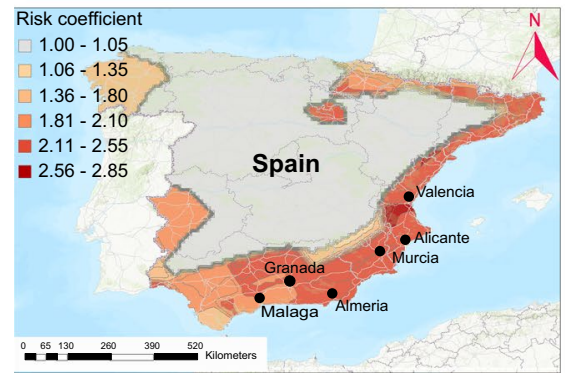

(b)

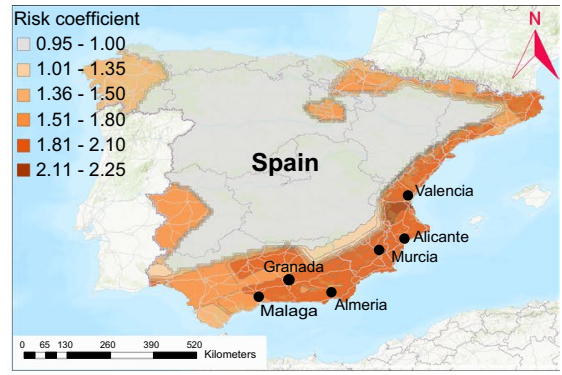

(d)

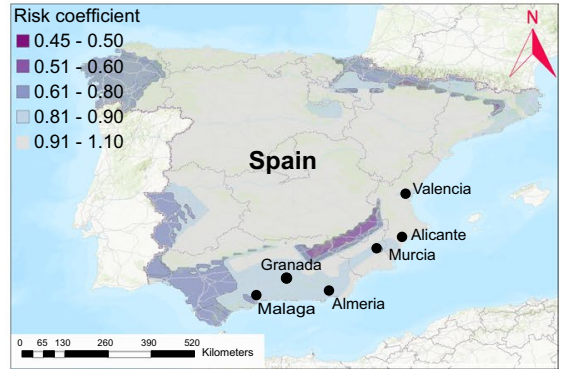

Fig. 7 Distribution of risk coefficient considering different values of $\beta$ and $\mathrm{P}_{\mathrm{c}} \operatorname{lgm}$ (case 1 to 4 ) according to Table 4 for peninsular Spain a Case 1, b Case 2, c Case 3, d Case 4

(a)

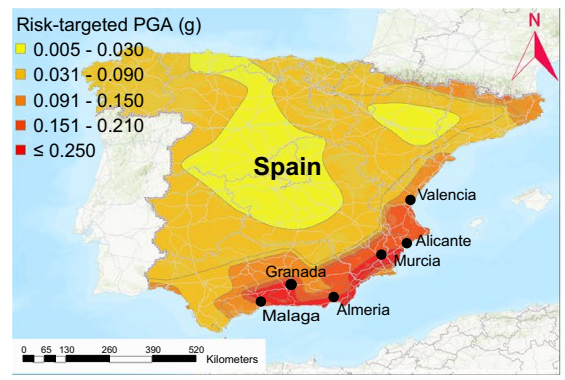

(b)

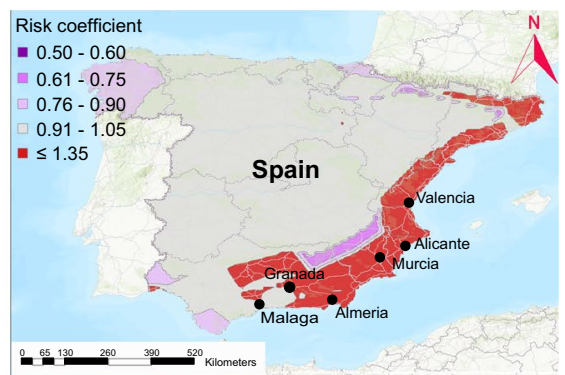

Fig. 8 Risk-targeted maps for Spain considering mean curve (fixed values $\beta=0.7, P_{c} \operatorname{lgm}=3 \times 10^{-4}$, and $\left.\lambda_{\mathrm{c}}=1.0 \times 10^{-5}\right)$ a Risk-targeted design ground motion, $\mathbf{b}$ Risk coefficient

parts of peninsular Spain, which are considered to be regions of low seismicity, the risk coefficient varies between 0.9 and 1.1. It should be outlined that the risk analysis with the collapse as a damage state does not significantly modify the uniform hazard design PGAs related to those regions of low seismicity. In contrast, most changes occurred in moderate to high seismic areas. Figure 10a, b compare the relationship between risk coefficient and uniform hazard design ground motion with a RP of 475 years according to the different types of fragility curves used for the risk analysis, i.e., a) mean curve 
(a)

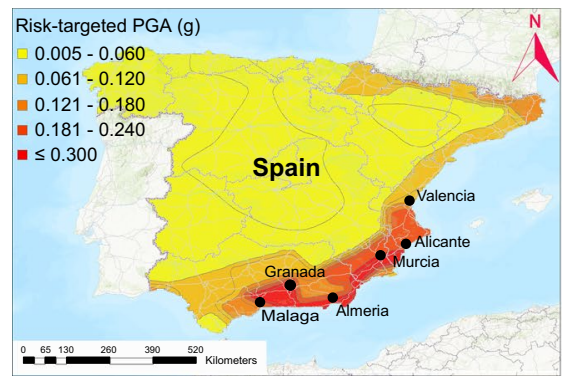

(b)

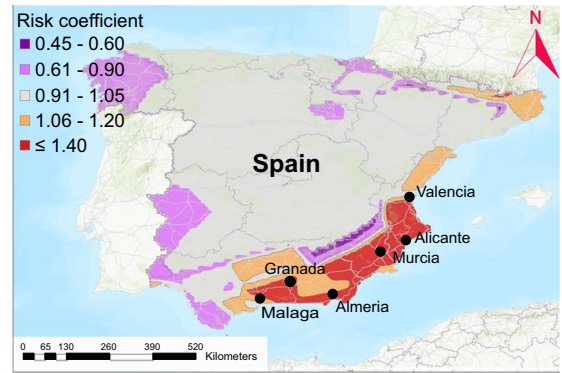

Fig. 9 Risk-targeted maps for peninsular Spain considering Crowley et al. (2018) fragility functions corresponding to each site a Risk-targeted design ground motion, b Risk coefficient

(a)

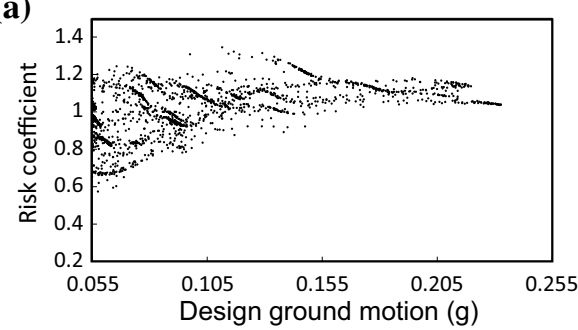

(b)

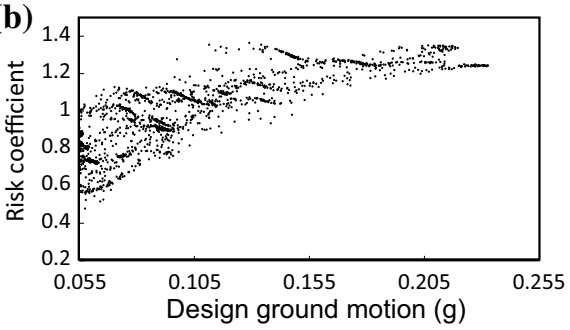

Fig. 10 Relation between risk coefficient and uniform hazard design ground motion a Considering mean curve (fixed values of $\mathrm{P}_{\mathrm{c}} \mathrm{lgm}$, and beta), b Considering Crowley et al. (2018) fragility curves corresponding to each site

(fixed values of $P_{c} \operatorname{lgm}$ and $\beta$ ) and $b$ ) building-site- specific fragility curve using the fragility functions of Crowley et al. (2018). From Figs. 9b and 10b, we can see that to reach a more uniform distribution of collapse risk, we should increase the uniform hazard design ground motion in areas of high seismicity and decrease them in low-to-moderate hazard regions. Moreover, this can be achieved by using the building- and sitespecific fragility curves. A comparison of the two figures (i.e., Fig. 10a, b) reveals that employing a unique fragility curve across the country leads to underestimated values of risk-targeted design ground motions in areas of moderate to high seismicity, while there is an opposite trend (i.e., overestimated values of risk-targeted design ground motion) for some low-hazard regions. This finding supports evidence from previous observations (e.g., Taherian and Kalantari 2021).

As shown in Fig. 10b, there is an opposite trend to what was presented by, for example, Douglas et al. (2013) for France. The reason for this opposite trend could be due to the relation between the risk of collapse and the design ground motions (Fig. 5b). The general trend in Fig. $5 b$ indicates an increase of the risk of collapse when increasing the ground motion. This outline is coherent with the findings of Iervolino et al. (2018). They demonstrated that the seismic risk of buildings is proportional to the seismic hazard of the site. According to the findings of the RINTC project (Iervolino et al. 2018), the seismic design of buildings for design PGA leads to considerably higher levels of seismic risk in areas of high hazard. As a result, to achieve a more uniform distribution of seismic risk, 
we should increase the design PGA in high-hazard regions while decreasing them in lowhazard regions.

Additionally, according to an update of the seismic hazard maps for peninsular Spain based on previous work by IGN-UPM Working Group (2013), strong earthquakes rarely occur in low-hazard areas. It means that the slope of the hazard curves for these areas could be almost steep. In other words, there is a small growth in design acceleration from a return period of 475 years to 2475 years, indicating that ground motions stronger than the design PGA have a lower impact on the annual collapse risk. Therefore, it could cause a lower risk of collapse. This contrasts with the moderate-hazard zones of peninsular Spain, where the slopes of the hazard curves are flat. These flat slopes could lead to a higher estimate of the risk of collapse. These outlines are coherent with the findings of Taherian and Kalantari (2021) as well as Martins et al. (2018).

Hence, the authors believe that, in previous studies considering the flat slope of hazard curves in low-hazard areas, a higher probability of collapse was estimated and vice versa. Therefore, if the mid-range of collapse risk is selected as the target risk, this leads to an increase in design PGA in low-hazard areas and decreasing design PGA in high-hazard cities. However, this is not the case for Spain based on the reasons mentioned above. The acceptable risk of collapse also determines how the design ground motion at a specific location should be modified to achieve a uniform risk distribution. This indicates that different trends can be observed based on the different thresholds.

Most design regulations enforce collapse prevention but do not provide sufficient specifications for damage limitation. Hence, as suggested by Douglas et al. (2013) and Silva et al. (2016), it would be essential to consider the yielding limit state in addition to the collapse limit state to define the acceptable structural performance in risk-targeted analysis. For this purpose, to estimate the target annual rate of exceeding yield damage state, values of $\beta$ and the probability of exceeding a damaged state (herein yielding) for a given design ground motion $\left(\mathrm{P}_{\mathrm{y}} \operatorname{lgm}\right)$ were assumed based on the work by Ulrich et al. (2014), where a set of fragility curves was developed for a regular three-story RC moment frame building designed using EC2 and EC8. Fragility functions of Ulrich et al. (2014) were taken into account since these are based on a simple and straightforward approach. Moreover, Martins et al. (2018) found little variation between the average values of model parameters of fragility curves for yielding damage state corresponded to differently designed buildings. Hence, in this part, we assumed the values mentioned by Ulrich et al. (2014) for $\beta$ and $\mathrm{P}_{\mathrm{y}} \operatorname{lgm}$. Using the considered values for later parameters and since in Eurocode 8, the damage limitation was introduced for ground motions with $10 \%$ probability of exceedance in ten years (95-year return period), the same approach from Luco et al. (2007) was adapted to estimate the acceptable annual risk of yield. The obtained results show that the average annual risk of yielding is $1.8 \times 10^{-4}$, and the maximum and minimum values are $9.25 \times 10^{-4}$ and $2.4 \times 10^{-5}$, respectively. Based on the obtained results, we assume a value of $1.8 \times 10^{-4}$ for the annual target risk of yielding.

Finally, assuming that the $\beta$ and $\mathrm{P}_{\mathrm{y}} \operatorname{lgm}$ values proposed by Ulrich et al. (2014) according to the related design ground motion and target annual yielding risk $\left(\lambda_{\mathrm{y}}\right)$ of $1.8 \times 10^{-4}$, the risk-targeted ground motion maps were developed. The results of these analyses are shown in Fig. 11. Figure 11a, b display the risk coefficient distribution and the corresponding uniform hazard PGA with a mean return period of 95 years for peninsular Spain.

Figure $11 \mathrm{a}, \mathrm{b}$ show that assuming a target annual yielding risk $\left(\lambda_{\mathrm{y}}\right)$ of $1.8 \times 10^{-4}$ leads to a significant modification of design ground motions across the regions with low or moderate seismicity. In contrast, as expected, Fig. 11a displays an increase of design ground motion in areas with high seismicity to design buildings with a uniform risk of yielding. A 
(a)

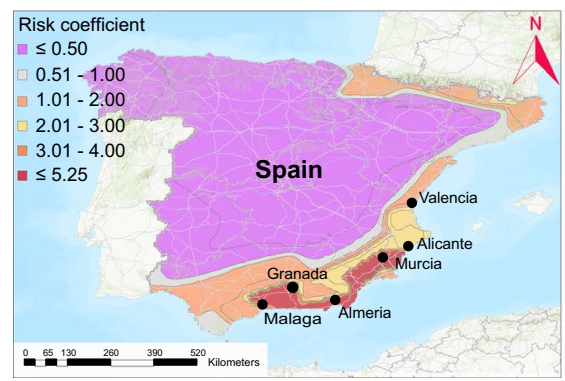

(b)

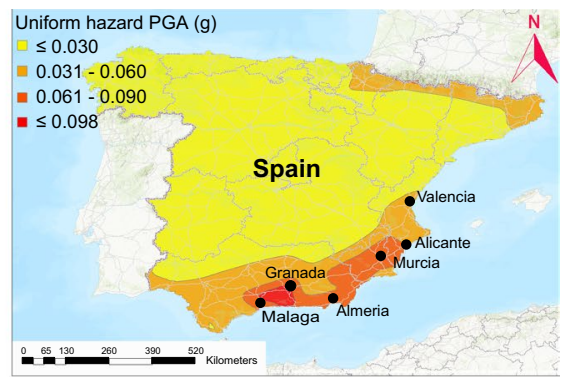

Fig. 11 Risk targeted maps for peninsular Spain (yielding considered for damage state) a Risk Coefficient distribution $\left(\lambda_{\mathrm{y}}=1.8 \times 10^{-4}\right)$, b Uniform hazard map (PGA $(\mathrm{g})$ at rock) with $10 \%$ probability of exceedance in 10 years

comparison of Fig. 11a and Figures $8 \mathrm{~b}$ or $9 \mathrm{~b}$ also confirms the suggestion by Douglas et al. (2013) and Silva et al. (2016) to consider the yielding limit state in addition to the collapse one to define the acceptable structural performance in risk-targeted analysis.

To investigate the variation in the design ground motions with respect to the uniform hazard PGAs, statistical information related to the risk coefficient in the two assumed damage states (Table 5) shows that in the collapse performance, the risk coefficient varies between 0.48 and 1.37, while for the yielding state, this coefficient ranges between 0.064 and 5.25. Moreover, the coefficient of variation for the yielding damage state is significantly higher than the one for collapse risk. This indicates that, since most of Spain's areas are regions with low or moderate seismicity, the modification of design ground motions corresponding to the yield state is more considerable than for collapse.

Table 6 shows the risk coefficient for different performance levels (i.e., collapse and yielding) corresponding to the cities with the highest seismic hazard, i.e., Valencia, Alicante, Murcia, Almeria, Granada, and Malaga (Fig. 1).

As shown in Table 6, the results confirm the previous outline. The modification of design ground motions corresponding to the yield damage states is more considerable than for collapse. Moreover, it can be observed that the PGA design should be increased for almost all the cities mentioned above, either for collapse or yielding performance. There

Table 5 Statistical results obtained from the risk analysis for Spain (risk coefficient)

\begin{tabular}{llllll}
\hline Damage state & Max & Min & Median & Mean & CoV* \\
\hline Collapse & 1.37 & 0.48 & 1.0 & 0.99 & 0.13 \\
Yielding & 5.25 & 0.064 & 0.49 & 0.92 & 1.16 \\
\hline
\end{tabular}

*CoV: Coefficient of Variation

Table 6 Risk coefficient for different performance levels

\begin{tabular}{lllllll}
\hline Performance level & \multicolumn{1}{l}{ Cities } & & & & \\
\cline { 2 - 7 } & Valencia & Alicante & Murcia & Almeria & Granada & Malaga \\
\hline Collapse & 1.22 & 1.26 & 1.34 & 1.27 & 1.24 & 1.04 \\
Yielding & 2.45 & 2.89 & 5.10 & 4.75 & 4.75 & 2.27 \\
\hline
\end{tabular}


is only one exception for Malaga, where there is almost no need for any modification corresponding to the collapse damage state. According to Table 6, Murcia shows the highest increase in design PGA among the cities with high seismic risk. Here, during the Lorca earthquake (11 May 2011, Mw=5.1), most of the buildings in the Lorca city (Murcia) had reinforced concrete (RC) structures, which, due to their design, combined with the severity of the earthquake tremors, were at serious risk of collapse. Many had to be subsequently demolished, and others needed retrofitting (Ruiz-Pinilla et al. 2016). Therefore, this increase in design PGA seems reasonable and necessary.

Clearly, the results of risk-targeted maps would be considerably different when varying $\mathrm{P}_{\mathrm{c}} \operatorname{lgm}, \beta$, and the acceptable risk thresholds. We also believe that changing the considered typology from RC moment frames into, for instance, masonry (the second most familiar building typology in Spain) could also provide completely different results due to the variation in model parameters of the corresponding fragility curves.

\section{Conclusions}

In this study, risk-targeted maps were developed based on an updated seismic hazard map of Spain. The annual risk was calculated by using the convolution product between seismic hazard and fragility functions. Two structural performances were considered, namely collapse and yielding. Regarding the collapse as a damage state, to consider the variability of the relevant parameters for developing the fragility curves, a multivariant normal distribution of input parameters (e.g., $\beta$ and $\mathrm{P}_{\mathrm{c}} \operatorname{lgm}$ ) was employed. The framework was based on the information provided by Martins et al. (2018). The effect of variations in the $\beta$ and $\mathrm{P}_{\mathrm{c}} \operatorname{lgm}$ parameters on the risk analysis results was investigated by considering different values and assumptions, i.e., a fixed value or building- and site-specific fragility models.

Regarding the yielding damage state, since previous studies (e.g. Martins et al. 2018) have indicated that there is little variation between the relevant input parameters of fragility curves, the values proposed by Ulrich et al. (2014) were considered to perform the risk analysis. To calculate the acceptable threshold for the annual risk of exceeding the damage state, a framework similar to that of Luco et al. (2007) was followed. Furthermore, the risktargeted ground motion maps were revealed by considering an acceptable structural performance, and the approach was explained earlier in previous sections. The results highlight these remarks as follows:

- As expected, the structural design based on a ground motion for a given RP results in an annual probability of exceeding a damage state that varies from one area to another. This confirms that the annual risk of collapse depends not only on the ground motion design but also on the shape of the hazard curves in those areas. Of course, the effect of uncertainty on the capacity of structures should not be dismissed.

- The current findings support the relevance of the standard deviation of the fragility curve, $\beta$. The larger the $\beta$ value, the lower the risk-targeted ground motion design relative to the uniform hazard map.

- $\mathrm{P}_{\mathrm{c}} \operatorname{lgm}$ makes a significant difference to the annual collapse risk. For a given value of acceptable collapse probability and standard deviation, the design ground motion level leads to larger values by increasing the value of $\mathrm{P}_{\mathrm{c}} \operatorname{lgm}$.

- This investigation shows that using a fixed value of $\beta$ and $\mathrm{P}_{\mathrm{c}} \operatorname{lgm}$ cannot provide an annual risk of collapse in line with the UHGM map. Moreover, it could lead to an 
overestimation or underestimation of the collapse risk in some low- or high-hazard areas, respectively.

- The relationship between the design ground motion and the risk of collapse in peninsular Spain confirms that the more the design ground motion, the higher the risk of collapse. Therefore, if the mid-range of collapse risk as a target risk is selected, this leads to a decrease in design PGAs in low-hazard areas and, conversely, increasing design PGAs in high-hazard cities.

- Given that these parameters (i.e., acceptable risk probability, standard deviation, and threshold of damage state probability for a given design ground motion) can allocate different values, other risk-targeted maps would be obtained for the regions considered in this study.

- When collapse is assumed as a damage state, the most significant variation in the design ground motion is related to high-seismicity areas in Spain. In contrast, areas with low or moderate seismicity are only slightly affected.

- The modification of design ground motions for low- and moderate-hazard risk regions corresponding to the yield state is more substantial than for the collapse state.

- The most obvious finding to emerge from this study is that to perform a risk analysis, it is strongly recommended to use fragility models according to the specific typology and commensurate with the design ground motion of that region.

These results show that the use of a different damage state as a structural performance is necessary to develop risk-targeted maps for the design of new buildings. Moreover, the authors also believe that since masonry buildings are the second most common type in Spain, considering different typologies instead of RC moment frames can also provide completely different results due to the variation in model parameters of corresponding fragility curves. Further research is needed to establish a clear link between design ground motion at each site and the model parameters of fragility curves similar to the works done by Martins et al. (2018) and Crowley et al. (2018). The simple relationships between design ground motion and model parameters of fragility curves for a specified typology lead to low computational costs. In addition, it should be mentioned that in this study, calculations were performed assuming rock site conditions. It seems further research is needed to assess the effect of local site conditions.

Acknowledgements The authors wish to acknowledge Dr. Vitor Silva and other reviewers as well as Dr. John Douglas for fruitful comments on the manuscript that helped us to improve it. In addition, we thank Dr. Dominik Lang for an extensive language and grammar review.

Funding The study has received funding from the European Union's Horizon 2020 research and innovation program under grant agreement No 821046, the Ministerio de Economía, Industria y Competitividad through research project CGL2016-77688-R, with the collaboration and funding provided by Elche and Alicante municipalities. Open Access funding provided thanks to the CRUE-CSIC agreement with Springer Nature.

Open Access This article is licensed under a Creative Commons Attribution 4.0 International License, which permits use, sharing, adaptation, distribution and reproduction in any medium or format, as long as you give appropriate credit to the original author(s) and the source, provide a link to the Creative Commons licence, and indicate if changes were made. The images or other third party material in this article are included in the article's Creative Commons licence, unless indicated otherwise in a credit line to the material. If material is not included in the article's Creative Commons licence and your intended use is not permitted by statutory regulation or exceeds the permitted use, you will need to obtain permission directly from the copyright holder. To view a copy of this licence, visit http://creativecommons.org/licenses/by/4.0/. 


\section{References}

ASCE (2016) ASCE STANDARD Minimum design loads and associated criteria for buildings and other structures. American Society of Civil Engineers, Reston

Crowley H, Silva V, Martins L (2018) Seismic Design Code Calibration Based on Individual and Societal Risk. 16th Eur Conf Earthq Eng 173-222

Dolsek M (2009) Incremental dynamic analysis with consideration of modeling uncertainties. Earthq Eng Struct Dyn 38:805-825. https://doi.org/10.1002/eqe.869

Douglas J, Gkimprixis A (2018) Risk targeting in seismic design codes: the state of the art, outstanding issues and possible paths forward. Nat Hazards. https://doi.org/10.1007/978-3-319-74724-8_14

Douglas J, Ulrich T, Negulescu C (2013) Risk-targeted seismic design maps for mainland France. Nat Hazards 65:1999-2013. https://doi.org/10.1007/s11069-012-0460-6

Douglas J, Gkimprixis A, Tubaldi E (2019) Derivation of risk-targeted maps for Italy based on a simplified approach. Atti del XVIII Convegno ANIDIS L'ingegneria Sismica in Italia : Ascoli Piceno. Pisa University Press, Pisa, pp 15-19

Eads L, Miranda E, Krawinkler H, Lignos DG (2013) An efficient method for estimating the collapse risk of structures in seismic regions. Earthq Eng Struct Dyn 42:25-41. https://doi.org/10.1002/eqe. 2191

EN-1998 (2005) Eurocode 8: Design of structures for earthquake resistance. European Committee for Standardization

Fajfar P, Dolšek M (2012) A practice-oriented estimation of the failure probability of building structures. Earthq Eng Struct Dyn 41(531):547. https://doi.org/10.1002/eqe.1143

Garcia-Mayordome J (2015) Creación de un modelo de zonas sismogénicas para el cálculo del mapa de peligrosidad sísmica de España. Instituto Geológico y Minero de España, IGME, Madrid

Gkimprixis A, Tubaldi E, Douglas J (2019) Comparison of methods to develop risk-targeted seismic design maps. Bull Earthq Eng 17:3727-3752. https://doi.org/10.1007/s10518-019-00629-w

Gkimprixis A, Tubaldi E, Douglas J (2020) Evaluating alternative approaches for the seismic design of structures. Bull Earthquake Eng 18:4331-4361

Iervolino I, Spillatura A, Bazzurro P (2018) Seismic Reliability of Code-Conforming Italian Buildings. J Earthq Eng 22:5-27. https://doi.org/10.1080/13632469.2018.1540372

IGME (2015) ZESIS: Base de Datos de Zonas Sismogénicas de la Península Ibérica y territorios de influencia para el cálculo de la peligrosidad sísmica en España. http://info.igme.es/zesis

IGN-UPM Working Group (2013) Actualización de Mapas de Peligrosidad Sísmica de España 2012. IGME, Madrid

Jalayer F, Cornell CA (2003) A technical framework for probability-based demand and capacity factor design (DCFD) seismic formats. PEER Rep 8:122

Kennedy RP (2011) Performance-goal based (risk informed) approach for establishing the SSE site specific response spectrum for future nuclear power plants. Nucl Eng Des 241:648-656. https://doi. org/10.1016/j.nucengdes.2010.08.001

Liel AB, Haselton CB, Deierlein GG, Baker JW (2009) Incorporating modeling uncertainties in the assessment of seismic collapse risk of buildings. Struct Saf 31:197-211. https://doi.org/10.1016/j. strusafe.2008.06.002

Luco N, Ellingwood BR, Hamburger RO, et al (2007) Risk-targeted versus current seismic design maps for the conterminous united states. Struct Eng Assoc Calif 2007 Conv Proc 1-13

Martins L, Silva V, Bazzurro P, Marques M (2018) Advances in the derivation of fragility functions for the development of risk-targeted hazard maps. Eng Struct 173:669-680. https://doi.org/10.1016/j. engstruct.2018.07.028

Mezcua J, Rueda J, Blanco RMG (2004) Reevaluation of historic earthquakes in Spain. Seismol Res Lett 75:75-81. https://doi.org/10.1785/gssrl.75.1.75

Ordaz M, Martinelli F, D'Amico V, Meletti C (2013) CRISIS2008: a flexible tool to perform probabilistic seismic hazard assessment. Seismol Res Lett 84:495-504. https://doi.org/10.1785/0220120067

Pavel F, Vacareanu R, Douglas J et al (2016) An updated probabilistic seismic hazard assessment for romania and comparison with the approach and outcomes of the SHARE project. Pure Appl Geophys 173:1881-1905. https://doi.org/10.1007/s00024-015-1223-6

Ruiz-Pinilla JG, Adam JM, Pérez-Cárcel R et al (2016) Learning from RC building structures damaged by the earthquake in Lorca, Spain, in 2011. Eng Fail Anal 68:76-86. https://doi.org/10.1016/j.engfa ilanal.2016.05.013

Silva V, Crowley H, Bazzurro P (2016) Exploring risk-targeted hazard maps for Europe. Earthq Spectra 32:1165-1186. https://doi.org/10.1193/112514EQS198M 
Sousa L, Silva V, Marques M, Crowley H (2016) On the treatment of uncertainties in the development of fragility functions for earthquake loss estimation of building portfolios. Earthq Eng Struct Dyn 45:1955-1976. https://doi.org/10.1002/eqe.2734

Spillatura A (2018) From record selection to risk targeted spectra for risk-based assessment and design. Ph.D. Thesis, Dipartimento di Costruzionie Infrastrutture, Istituto Universitario degliStudi Superiori (IUSS), Pavia, Italy

Taherian AR, Kalantari A (2019) Risk-targeted seismic design maps for Iran. J Seismol 23:1299-1311. https://doi.org/10.1007/s10950-019-09867-6

Taherian AR, Kalantari A (2021) Analysis of the risk-targeting approach to defining ground motion for seismic design: a case study of Iran. Bull Earthq Eng. https://doi.org/10.1007/s10518-020-01023-7

Ulrich T, Negulescu C, Douglas J (2014) Fragility curves for risk-targeted seismic design maps. Bull Earthq Eng 12:1479-1491. https://doi.org/10.1007/s10518-013-9572-y

Vacareanu R, Pavel F, Craciun I et al (2018) Risk-targeted maps for Romania. J Seismol 22:407-417. https:// doi.org/10.1007/s10950-017-9713-X

Vanzi I, Marano GC, Monti G, Nuti C (2015) A synthetic formulation for the Italian seismic hazard and code implications for the seismic risk. Soil Dyn Earthq Eng 77:111-122. https://doi.org/10.1016/j. soildyn.2015.05.001

Zaman M, Ghayamghamian MR (2019) Risk-adjusted design basis earthquake: a case study of Tehran megacity. Bull Earthq Eng 17:3777-3799. https://doi.org/10.1007/s10518-019-00625-0

Publisher's Note Springer Nature remains neutral with regard to jurisdictional claims in published maps and institutional affiliations.

\section{Authors and Affiliations}

\section{A. Kharazian ${ }^{1}$ - S. Molina ${ }^{1,3} \cdot$ J. J. Galiana-Merino ${ }^{2,4} \cdot$ N. Agea-Medina ${ }^{1}$}

\section{S. Molina}

sergio.molina@gcloud.ua.es

\section{J. J. Galiana-Merino}

jj.galiana@ua.es

N. Agea-Medina

noelia.agea@ua.es

1 Multidisciplinary Institute for Environmental Studies Ramon Magalef (IMEM), University of Alicante, Alicante, Spain

2 University Institute of Physics Applied To Sciences and Technolgies, University of Alicante, Alicante, Spain

3 Dept. Applied Physics Faculty of Sciences, University of Alicante, Alicante, Spain

4 Dept. Physics, Systems Engineering, and Signal Theory, Polytechnic School, University of Alicante, Alicante, Spain 